Moewes, Grundfragen der Lebensraumgestaltung 



\section{Winfried Moewes}

\section{Grundfragen der \\ Lebensraumgestaltung}

Raum und Mensch, Prognose, "offene“ Planung und Leitbild

Mit einem Vorwort von K. R. Popper

\footnotetext{
$\mathrm{W}$
$\mathrm{DE}$

G Berlin - New York 1980
} 
Dr. rer. nat. Winfried Moewes

Prof. für Angewandte Geographie und Regionalplanung, Justus-Liebig-Universität Gießen

Für Gabriele, Henning und Olaf

CIP-Kurztitelaufnahme der Deutschen Bibliothek

\section{Moewes, Winfried:}

Grundfragen der Lebensraumgestaltung: Raum u. Mensch, Prognose, ,offene" Planung u. Leitbild / Winfried Moewes. mit e. Vorw. von K. R. Popper.

- Berlin, New York: de Gruyter, 1980.

ISBN 3-11-007960-7

(C) Copyright 1980 by Walter de Gruyter \& Co., vormals G. J. Göschen'sche Verlagshandlung, J. Guttentag, Verlagsbuchhandlung Georg Reimer, Karl J. Trübner, Veit \& Comp., Berlin 30. Alle Rechte, insbesondere das Recht der Vervielfältigung und Verbreitung sowie der Úbersetzung, vorbehalten. Kein Teil des Werkes darf in irgendeiner Form (durch Photokopie, Mikrofilm oder ein anderes Verfahren) ohne schriftliche Genehmigung des Verlages reproduziert oder unter Verwendung elektronischer Systeme verarbeitet, vervielfältigt oder verbreitet werden. Printed in Germany.

Satz und Druck: Druckerei Wagner, Nördlingen.

Bindearbeiten: Lüderitz \& Bauer Buchgewerbe GmbH, Berlin. 